\title{
Drifting with the Dharma: D.T. Suzuki and Historical Japanese Zen Contributions to Modern Mindfulness Science
}

Joseph Ring

Institute of Social Sciences, Toyo University

Follow this and additional works at: https://gensoken.toyo.ac.jp/japanese-society-and-culture

Part of the Japanese Studies Commons

\section{Recommended Citation}

Ring, Joseph (2019) "Drifting with the Dharma: D.T. Suzuki and Historical Japanese Zen Contributions to Modern Mindfulness Science," Japanese Society and Culture: Vol. 1 , Article 2.

DOI: 10.52882/2434-1738-1

Available at: https://gensoken.toyo.ac.jp/japanese-society-and-culture/vol1/iss1/2

This Article is brought to you for free and open access by Institute of Social Sciences. It has been accepted for inclusion in Japanese Society and Culture by an authorized editor of Institute of Social Sciences. 


\title{
Drifting with the Dharma: \\ D.T. Suzuki and Historical \\ Japanese Zen Contributions to Modern Mindfulness Science
}

Joseph Ring*

"To find the Dharma, drift east and west, come and go, entrust yourself to the waves"

Ryokan Taigu (1758-1831)

"Toti se inserens mundo"

Seneca the Younger (c. 4 B.C.E. - 65 C.E.)

\begin{abstract}
The purpose of this paper is to familiarize researchers, scholars, and interested readers with the historical influence of Japanese Buddhist Zen meditation techniques on mindfulness-based stress reduction (MBSR) research and practice. The role of D.T. Suzuki is discussed as one of the most influential scholars to transmit information to the West. MBSR techniques, format, and evidence are also explicated.
\end{abstract}

Key words: Mindfulness-based stress reduction, history of Zen, education, positive psychology

\section{Introduction}

In this article, I will discuss the contribution of Japanese Zen to the science of the current Mindfulness-Based Stress Reduction movement (MBSR) with a selected focus upon the influence of D. T. Suzuki. I will give a review of the history of Japanese Zen's influence upon Western psychology, introduce the two major schools of Japanese Zen, and discuss the basic concepts and practices of Zen. I will discuss the current operational definition (that is to say, the formal definition used for research purposes) of mindfulness, and give a selected review of two meta-analyses conducted upon the effectiveness of MBSR. Though there have been many other influential Buddhist contributions to the MBSR research literature such as the efforts of the Dalai Lama in the Tibetan tradition and Thich Nhat Hanh who has created what he calls "engaged Buddhism," I will limit this monograph to a discussion of Japanese Zen influence as represented by the scholarship of D.T. Suzuki.

\footnotetext{
※ Visiting Reseacher, Institute social sciences, Toyo University.
} 


\section{Background}

William James once suggested, that "the faculty of voluntarily bringing back a wandering attention, over and over again, is the very root of judgement, character, and will. No one is compos sui if he have it not. An education which would improve this faculty would be the education par excellence. But it is easier to define this ideal than to give practical directions for bringing it about (James, 1890, p. 424)". This statement was made at a time in history when the type of method for focusing the mind that James was seeking was still relatively unknown in the North American and European contexts. However the following decades have led to developments in study and research in the "consciousness disciplines" (Walsh, 1980), especially mindfulness-based stress reduction, that supply the "practical directions" that James sought. Mindfulness-based stress reduction has deep roots in Zen Buddhist meditative practice. Below, I take up the historical roots of the modern day practice of Mindfulness-based stress reduction and, in particular, the Japanese contribution thereunto through the scholarship of D. T. Suzuki.

It is something of a historical irony that Buddhism was initially condemned in the early stages of the Meiji era as a "foreign" religion and a target for elimination in Japan (Sharf, 1993, p. 3) and yet is beginning to have an influence upon the current scientific movement to study the effects of meditation upon the body/brain and phenomenology of consciousness. How did Buddhism survive and come to have such a large influence on the behavioral and medical sciences in the last few decades around the world? I take up that issue below, especially as the issue pertains to Zen Buddhism. But first, what are the basic techniques of Zen that have been the relatively recent source of scientific interest?

\section{Basic Techniques in Zen}

To begin with, the word "Zen" is a transliteration of the Chinese word "Chan" which in turn originally comes from the Sanskrit word "Dhyana." All simply mean meditation. "Zazen" means "seated meditation". In formal meditation, one takes a seated cross-legged position in the half- or full-lotus posture, or in a chair if one is unable to sit in a cross-legged fashion. This is called "shikantaza" or "just sitting". One then focuses on just breathing, typically by paying attention to the breath as felt when is passes through the nostrils or as felt in the abdomen when the abdomen rises and falls, ideally achieving a natural, unforced breathing cycle.

In the Soto School of Zen, the indigenous school of Japanese Buddhism, founded by Dogen Zenji in the early $1200 \mathrm{~s}$. The meditation sessions are typically 50 minutes at time followed by 10 minutes of walking meditation. Dogen focused primarily on the practice of seated meditation as being closer to the actual practice of the historical Buddha based upon Dogen's studies and experiences at temples in China. The Rinzai School in Japan was founded by Myoan Eisai at the end of the 1100s based upon his experiences in China. In the Rinzai School, the meditation sessions may be shorter and also include the extensive use of koans. A koan is a type of riddle utilized to assist the meditator in their practice.

To illustrate in detail a technique from the Soto tradition, I will discuss a technique called "susokukan" which is taught in both schools. This is a technique taught to beginners in order to assist them in focusing upon the breath. When one's mind wanders, which one current research 
study suggests is approximately $47 \%$ of the day in the normal population regardless of the activity (Killingsworth \& Gilbert, 2010), one brings attention to one's breath and counts each one upon inhalation, exhalation or both. The practitioner generally counts to 10 and then begins again until concentration is stable. If concentration is again disrupted whilst counting, one gently and nonjudgementally returns to counting again.

Though there are differing approaches and opinions as to what exactly constitutes the essence of Zen Buddhism, there seems to be general agreement in the literature that Daisetsu Teitarō Suzuki (1870-1966) was one of the more important figures in transmitting knowledge of Buddhism and Zen practices abroad from Japan through the many books that he published. One author has stated that Suzuki, for better or for worse, "practically defined the meaning of Zen for western audiences" (Nāgapriya, 2012, p.1). According to Sharf, "The notion that Zen is somehow related to Japanese culture in general, and bushido in particular, is familiar to Western students of Zen through the writings of D. T. Suzuki, no doubt the single most important figure in the spread of Zen in the West" (Sharf, 1993, p. 12).

\section{Zen from Meiji Japan to the World}

Much of Suzuki's work came to the fore after the Second World War in the 1950s and 1960s, especially in the USA (Pinder, 2008). Suzuki published more than 30 books on Buddhism and had more than 100 publications on Buddhism and other schools of thought such as Lao Tsu in Japanese and English, according to Sharf (2017). As a result of this interest, Zen methods began to be studied and adopted by therapists and psychologists, especially those applying an existentialist-humanistic model to deal with "the supposed root causes of patients' spiritual emptiness, anxiety, and alienation" (Harrington, 2016, p. 4). Suzuki influenced many of the well-known thinkers of the day such as Erich Fromm, Martin Heidegger, Karl Jaspers, Thomas Merton, C.G. Jung, Jack Kerouac, Alan Ginsberg, and Gary Snyder to give some examples from psychology, philosophy and poetry. Suzuki's works also influenced the work of psychoanalysts as instanced by Horney's statement that clinicians should listen with "whole hearted attentiveness" (as cited in Harrington, 2016, p. 17) similar to a Zen practitioner.

Though many other thinkers helped to create the conditions during the preceding decades leading to the introduction of Zen meditative techniques into the current day fields of psychology, psychiatry, and education, to name but a few, Suzuki's work was timely, influential, and representative of Japanese thought about Buddhism as the Japanese intelligentsia of that age understood it. Pertaining to Suzuki's influence on psychology and psychotherapy, Harrington has stated, "It was Suzuki who, more than anyone else, first encouraged American psychotherapists to think of Zen as psychotherapy by other means, and the Asian religious traditions as a resource, not just for spiritual insights, but also for clinical projects. Even if today we are more inclined to talk about 'Zen and the brain' than about Zen and the unconscious, we still work with a range of assumptions about Zen as a psychology and a therapeutic path that he first helped to articulate" (Harrington, 2016, p. 23).

As mentioned in the introduction, it was an open question in the preceding Meiji Era whether or not Buddhism would survive government policy upon its native heath. Nevertheless, by adapting 
to the imperialist government agenda (Sharf, 1993) and the transmission of information abroad through the efforts of scholars like Suzuki, Japanese Buddhist and Zen thought and practices were able to expand their influence. As this is an introductory monograph, I refer the interested reader to Dumoulin (1989), Nāgapriya, (2012) and Sharf (1993), for an in-depth treatment on the history of Zen Buddhism and the transmission of it to other countries. Next, I turn to a discussion of one of the psychological treatment methods that has emerged from the Zen intellectual and meditative milieu, namely, mindfulness-based stress reduction (Kabat-Zinn, 1982).

\section{MBSR: Breath, Body, and Mind Operationalized for Scientific Research}

In 1979, John Kabat-Zinn pioneered MBSR which is, perhaps, the most influential approach today towards self-management of the mind for stress reduction purposes. He created the secular MBSR technique based upon his personal meditation experiences. He created this technique as a means of alleviating chronic stress and pain for the benefit of his patients at the University of Massachusetts Medical Center (Husgafvel, 2016). Next, I give Kabat-Zinn's current definition of MBSR as it is operationalized (i.e. formally defined for the purpose of scientific research). After that, I describe the format and elements of the MBSR program.

Following that, I give some current, prevalent example definitions as operationalized for scientific research.

In the original 1982 research, Kabat-Zinn described mindfulness meditation as the process wherein, "the meditator simply brings attention to a detail of momentary reality, usually the breath or a sensation, to (re)anchor the attention in the present" (p. 34). This definition was further clarified and updated in 2003 as: "the awareness that emerges through paying attention on purpose, in the present moment, and nonjudgementally to the unfolding of experience moment by moment" (p. 145). Kabat-Zinn sees this as the essence of Buddhist meditation and chose this approach as the basis for creating this type of mental and physical health intervention. However, MBSR is a secular, scientific approach and therefore as such "it should also be noted, being about attention, is also of necessity universal. There is nothing particularly Buddhist about it. We are all mindful to one degree or another, moment by moment. It is an inherent human capacity" (Kabat-Zinn, 2003, p. 146).

Another well-known form of mindfulness training is mindfulness-based cognitive therapy applied to those who have become clinically depressed (MCBT; Segal, Williams, \& Teasdale, 2002). It is a combination of cognitive based therapy or CBT developed by Beck (Beck, 1979) and MBSR. For instance, there is research data that indicates a reduced rate of relapse 15 months posttreatment of $47 \%$ with MCBT versus $60 \%$ with antidepressant medication alone (Kuyken et al., 2008). If further research evidence continues to support such long term positive change for one of the most severe of human psychological conditions, then MCBT has potential to alleviate the long term suffering of those vulnerable to depression. MBSR and MCBT have also been applied in a variety of other arenas and populations such as the workplace, prisons, schools, the military, and in athletics. For more historical background and discussion, c.f. The Wiley Blackwell Handbook of Mindfulness, (Ie, Ngnoumen, \& Langer, 2014) and Mindfulness and Learning (Hyland, 2011). 
What follows next is a basic description of the MBSR program used in teaching people how to alleviate stress. The original Mindfulness-Based Stress Reduction Program (Kabat-Zinn 1982; Kabat-Zinn 1990) is an intervention that has a group meeting once per week for 2.5 hours for eight weeks. It includes an all-day session which typically meets sometime during the sixth week. At each session, detailed instruction is given on the mindfulness practices. The practices include a body scan, yoga, walking meditation, and seated meditation. Participants are also encouraged to pursue their daily activities in a mindful manner such as eating, driving, and speaking, for instance (Kabat-Zinn, 1982). I describe the detailed practice next.

\section{MBSR in Detail}

First, I will explain the three basic structural elements of the original meditation program as originally applied by Kabat-Zinn (1982). The first element was originally called "sweeping" but is now generally called a "body scan". The original instructions for sweeping (henceforth body scan) consisted of "a gradual sweeping through the body from feet to head with the attentional faculty, focusing on proprioception, and with periodic suggestions of breath awareness and relaxation...usually practiced in the supine position" (p. 36). The second element is mindfulness of breath. The third element is Hatha Yoga conducted mindfully. As part of the mindfulness education, students were also taught to apply mindfulness during their daily activities such as eating, walking, and standing. Next, I report the meditation instructions given during the original MBSR program.

In the original program, participants were instructed in the following five areas in the process of meditation. First, bring one's attention to the breath or other object of focus. Second, pay attention to it one moment at a time. Third, if one notices that one's attention has wandered then try to gently, nonjudgementally return it to the object of attention. Fourth, if one experiences a strong emotion or feeling, guide one's attention to observing it as it is happening. The idea is to "just be with it, observing it. When it subsides, return to the primary object of observation. Distinguish between observation of the experience itself and thoughts and interpretations of the experience" (Kabat-Zinn, 1982, p. 36). Finally, the fifth instruction was to perceive the process of one's thoughts and note that the thoughts are impermanent and possibly not always accurate. Further to also note that any thought is of equal value to the others and do not follow or discard the thoughts as they arise.

Results from the original 1982 study indicated that greater than $50 \%$ of the participants reported at least a 33\% reduction in physical pains such as lower and upper back pain, shoulder pains, and headaches. In terms of psychological issues, such as depression, anxiety, and obsessivecompulsive disorder, $57 \%$ of the participants reported a reduction of at least $33 \%$ in their symptoms. A further $32 \%$ of participants reported a reduction of $50 \%$ or more.

The aforementioned elements remain intact as the core of the MBSR program though timing of delivery and dosage have changed since the program's inception. Furthermore, the original program was scheduled at 10 weeks but is now generally conducted in eight weeks. Finally, other features of the program that still remain include being delivered in a group format, clearly stating that participants can expect stress and pain relief from practicing body scans, practicing meditation, performing yoga, and having experienced, qualified instructors MBSR teachers. Furthermore, non- 
striving, self-responsibility, and taking a long-term perspective are still elements of the program as well. In conclusion, ongoing research and replication studies generally continue to support the effectiveness of the original MBSR 1982 results in a variety of populations. What follows in the next section is a brief explication of selected studies and meta-analyses in order to demonstrate how much research has been conducted in MBSR to date.

\section{Meta-analyses of MBSR}

There have been thousands of research projects conducted within the last few decades in MBSR. One meta-analysis (Pascoe, Thompson, Jenkins, \& Ski, 2017) that was conducted of randomized control trials or RCT (considered to be the most rigorous type of investigation or "gold standard" for research) studying the physiological markers of stress mediated via mindfulness gave a figure of 2,041 mindfulness research articles that are available. However that number was reduced to a final number of 45 because of those 2,041, there were 1,273 which were duplicate research articles. Furthermore, 80 were books, papers from conference proceedings, or theses that were eliminated from the meta-analysis. Other studies that did not meet the RCT standard such as the 43 which had no active control group or weaknesses due to study protocol eventuated in the number of 45 articles. The evidence found in these 45 articles indicated that mindfulness meditation mediated all of the biological markers associated with stress under investigation. For example, migraine headaches, obesity, type II diabetes, depression, blood pressure, cortisol, heart rate, and triglicerides were all reduced due to mindfulness meditation.

One further selected example of a meta-analysis (Grossman, Niemann, Schmidt, \& Walach, 2004) that investigated the influence of MBSR upon health related issues such as chronic illness, stress, cancer, and chronic pain will be discussed. Grossman et al. found a total of 64 articles that met the standards for inclusion in the meta-analysis. In the case of mental health variables, Grossman et al. found a medium strength effect size using Cohen's $d$, which is an effect size used in this case to indicate whether the mindfulness treatment statistical mean was above the control group statistical mean. Grossman et al. found a statistically significant effect of $d=0.54$ at the $P$ $<.0001$ level (p. 39) which indicates that an average person from the treatment group would have a higher score in mindfulness mediated symptoms than $69 \%$ of the people in the control group and is not likely to be due to random chance.

\section{Concluding Thoughts}

As a "consciousness discipline" (Walsh, 1980), mindfulness practice has become a strongly researched area in the human sciences. However, there is still much to learn from this discipline. For instance, how can mindfulness be applied in the field of positive psychology in education? For example, how does a high level of mindfulness correlate with self-efficacy? Are those with high hope also more mindful of pathways for goal accomplishment? Can mindfulness practice influence a person's use of time wisely as a resource? There are many questions in education alone which remain to be answered. D.T. Suzuki's efforts and scholarship in the preceding century have been the source of inspiration for the thinkers and Zen practitioners that followed. Perhaps future contributions to answering these research questions can be found by conducting research in 
educational settings in Japan in order to help support the MBSR research revolution it helped to nurture and that is well underway.

Dedication: With affection and love, I dedicate this article to my cousin N.L. You are a beacon of hope and an exemplar of kindness to all those ashore, at anchor, and adrift upon the Dharmic sea.

\section{REFERENCES}

Beck, A. T. (1979). Cognitive Therapy of Depression. Guilford Press.

Creswell, J. D. (2017). Mindfulness Interventions. Annual Review of Psychology, 68 (1), 491-516. https://doi.org/10.1146/annurev-psych-042716-051139

D. T. Suzuki - New World Encyclopedia. (2017). Retrieved November 26, 2018, from http://www.newworldencyclopedia.org/entry/D._T._Suzuki

Dumoulin, H., Heisig, J. W., \& Knitter, P. F. (1989). Zen Buddhism: a history. Macmillan.

Grossman, P., Niemann, L., Schmidt, S., \& Walach, H. (2004). Mindfulness-based stress reduction and health benefits: A meta-analysis. Journal of Psychosomatic Research, 57 (1), 35-43. https://doi.org/10.1016/S0022-3999(03)00573-7

Harrington, A. (2016). Zen, Suzuki, and the Art of Psychotherapy. Routledge. Retrieved from https://dash.harvard.edu/handle/1/30803001

Henderson, J. (2018, August 4). SENECA THE YOUNGER, Epistles. Retrieved August 4, 2018, from https://www.loebclassics.com/view/seneca_younger-epistles/1917/pb_LCL076.7.xml

Hofmann, S. G., Sawyer, A. T., Witt, A. A., \& Oh, D. (2010). The Effect of Mindfulness-Based Therapy on Anxiety and Depression: A Meta-Analytic Review. Journal of Consulting and Clinical Psychology, 78 (2), 169-183. https://doi.org/10.1037/a0018555

Husgafvel, V. (2016). On the Buddhist roots of contemporary non-religious mindfulness practice: Moving beyond sectarian and essentialist approaches. Temenos - Nordic Journal of Comparative Religion, $52(1), 87-126$.

Hyland, T. (2011). Mindfulness and Learning: Celebrating the Affective Dimension of Education. Springer Science \& Business Media.

Ie, A., Ngnoumen, C. T., \& Langer, E. J. (2014). The Wiley Blackwell Handbook of Mindfulness. John Wiley $\&$ Sons.

James, W. (1890). The Principles of Psychology. H. Holt.

Janssen, M., Heerkens, Y., Kuijer, W., van der Heijden, B., \& Engels, J. (2018). Effects of Mindfulness-Based Stress Reduction on employees' mental health: A systematic review. PLoS ONE, 13(1). https://doi.org/10.1371/journal.pone.0191332

Jones, L., \& Eliade, M. (2005). The encyclopedia of religion. Macmillan Reference USA.

Kabat-Zinn, J. (1982). An outpatient program in behavioral medicine for chronic pain patients based on the practice of mindfulness meditation: Theoretical considerations and preliminary results. General Hospital Psychiatry, 4(1), 33-47. https://doi.org/10.1016/0163-8343(82)90026-3

Kabat-Zinn, J. (2003). Mindfulness-based interventions in context: Past, present, and future. Clinical Psychology: Science and Practice, 10 (2), 144-156. https://doi.org/10.1093/clipsy/bpg016 
Keng, S.-L., Smoski, M. J., \& Robins, C. J. (2011). Effects of Mindfulness on Psychological Health: A Review of Empirical Studies. Clinical Psychology Review, 31 (6), 1041-1056. https://doi.org/10.1016/j.cpr.2011.04.006

Killingsworth, M. A., \& Gilbert, D. T. (2010). A Wandering Mind Is an Unhappy Mind. Science, 330 (6006), 932-932. https://doi.org/10.1126/science.1192439

Kuyken, W., Byford, S., Taylor, R. S., Watkins, E., Holden, E., White, K., Teasdale, J. D. (2008). Mindfulness-based Cognitive Therapy to Prevent Relapse in Recurrent Depression. Journal of Consulting and Clinical Psychology, 76 (6), 966-978. https://doi.org/10.1037/a0013786

Ma, S. H., \& Teasdale, J. D. (2004). Mindfulness-Based Cognitive Therapy for Depression: Replication and Exploration of Differential Relapse Prevention Effects. Journal of Consulting and Clinical Psychology, $72(1), 31-40$.

Miller, J. J., Fletcher, K., \& Kabat-Zinn, J. (1995). Three-year follow-up and clinical implications of a mindfulness meditation-based stress reduction intervention in the treatment of anxiety disorders. General Hospital Psychiatry, 17 (3), 192-200. https://doi.org/10.1016/0163-8343(95)00025-M

Nāgapriya, D. (2012). 1 Poisoned Pen Letters? D.T. Suzuki's Communication of Zen to the West.

Pascoe, M. C., Thompson, D. R., Jenkins, Z. M., \& Ski, C. F. (2017). Mindfulness mediates the physiological markers of stress: Systematic review and meta-analysis. Journal of Psychiatric Research, 95, 156178.

Pinder, C. (2008). Zen Buddhism and American Religious Culture: A Case Study of Daistez Teitaro Suzuki (1870-1966). Masters Theses. Retrieved from http://trace.tennessee.edu/utk_gradthes/428

Robb, S. W., Benson, K., Middleton, L., Meyers, C., \& Hébert, J. R. (2015). Mindfulness-based stress reduction teachers, practice characteristics, cancer incidence, and health: a nationwide ecological description. BMC Complementary and Alternative Medicine, 15 (1), 24. https://doi.org/10.1186/s12906-015-0545-3

Sharf, R. H. (1993). The Zen of Japanese Nationalism. History of Religions, 33 (1), 1-43.

Takao, H. (2001). Japan and the West in D. T. Suzuki's Nostalgic Double Journeys. The Eastern Buddhist, $33(2), 129-151$.

Walsh, R. (1980). The consciousness disciplines and the behavioral sciences: questions of comparison and assessment. American Journal of Psychiatry, 137(6), 663-673. https://doi.org/10.1176/ajp.137.6.663

Williams, J. M. G., \& Kabat-Zinn, J. (2011). Mindfulness: diverse perspectives on its meaning, origins, and multiple applications at the intersection of science and dharma. Contemporary Buddhism, 12 (1), 118. https://doi.org/10.1080/14639947.2011.564811

Williams, J. M. G., Russell, I., \& Russell, D. (2008). Mindfulness-Based Cognitive Therapy. Journal of Consulting and Clinical Psychology, 76 (3), 524-529. https://doi.org/10.1037/0022-006X.76.3.524 